\title{
A Performance Assessment Framework for Measuring Online Student Learn- ing Outcomes
}

\author{
Dr. Petronella A James, Morgan State University \\ Dr. Craig J. Scott, Morgan State University \\ Dr. Yacob Astatke, Morgan State University
}

Dr. Yacob Astatke completed both his Doctor of Engineering and B.S.E.E. degrees from Morgan State University (MSU) and his M.S.E.E. from Johns Hopkins University. He has been a full time faculty member in the Electrical and Computer Engineering (ECE) department at MSU since August 1994 and currently serves as the Associate Chair for Undergraduate Studies. Dr. Astatke is the winner of the 20122013 American Society for Engineering Education (ASEE) Mid-Atlantic Region Distinguished Teacher Award. He teaches courses in both analog and digital electronic circuit design and instrumentation, with a focus on wireless communication. He has more than 15 years experience in the development and delivery of synchronous and asynchronous web-based course supplements for electrical engineering courses. Dr. Astatke played a leading role in the development and implementation of the first completely online undergraduate ECE program in the State of Maryland. He has published over 40 papers and presented his research work at regional, national and international conferences. He also runs several exciting summer camps geared towards middle school, high school, and community college students to expose and increase their interest in pursuing Science Technology Engineering and Mathematics (STEM) fields. Dr. Astatke travels to Ethiopia every summer to provide training and guest lectures related to the use of the mobile laboratory technology and pedagogy to enhance the ECE curriculum at five different universities.

\section{Dr. Jumoke Oluwakemi Ladeji-Osias, Morgan State University}

Dr. Jumoke Ladeji-Osias is Associate Professor and Associate Chair for Graduate Studies in the Department of Electrical and Computer Engineering at Morgan State University. She earned in B.S. in electrical engineering from the University of Maryland, College Park and a Ph.D. in biomedical engineering from Rutgers, The State University of New Jersey. She coordinates the departmental graduate program and teaches both undergraduate and graduate courses in computer engineering, primarily in designing digital systems for hardware. She is the PI for Scholars in Engineering ( $\mathrm{SiE}$ ), an NSF S-STEMS scholarship for undergraduate and Master's students. She is a member of the Morgan team that is developing online laboratory courses for undergraduate students. Her research expertise is in algorithm optimization for FPGA implementation and her research group has developed a novel biologically inspired image fusion algorithm. She has over 35 journal and conference publications combined.

\section{Mrs. LaDawn E. Partlow M. Eng., Morgan State University \\ Dr. Kofi Nyarko, Morgan State University}




\section{A Performance Assessment Framework for Measuring Online Student Learning Outcomes}

\section{Introduction}

Trends in higher education for the past ten years have shown that enrollments in online courses or online degree programs have been growing substantially faster than overall higher education enrollment ${ }^{1}$. There are few if any Accreditation Board for Engineering and Technology (ABET) accredited programs that are completely online. Not only is there a need for innovative approaches and an ability to offer laboratory courses online, but there is a parallel need for assessment tools that allow the collection and analysis of course outcomes and objectives, in a seamless manner. A web-based assessment system might have more potential in terms of access and flexibility for teachers and administrators in terms of overall effectiveness and efficiency of producing "Learning Analytics" 2. Various approaches specifically geared toward helping programs document and measure ABET EC2000 program educational objectives and outcomes exsit ${ }^{3,4}$ but few such as Blackboard Learn and TK20 feature a fully electronic, rubric based approach that integrate well with existing student information systems ${ }^{5}$. The philosophy driving the approach in this work is to allow the instructor to focus on course outcomes via embedded problems and laboratory exercises while the program outcomes are derived from a mapping between the two levels. Subsequently, examining performance metrics and taking a proper course of action are conveniently done at all levels of administration. In this paper, assessment of online course student learning outcomes using a performance assessment framework (PAF) or Searchlight Performance Assessment ${ }^{\mathrm{TM}}$ ), which was developed with feedback from our institution, will be presented. This paper will give a firsthand view of how student assessment data is embedded, captured and analyzed, and how the data is aggregated and used to inform department progress. The paper will also review online course assessments for two academic years.

The performance assessment framework offers the means to perform program assessments through graphing both direct and indirect measures of course outcomes. At the program level, tabular and graphical outputs are created with drill down properties that allow one to determine the source of problematic results. The program outcomes are then mapped to each course with the associated performance criteria. The performance criteria measures specific outcomes that are determined through the use of electronic rubrics. Mapping and the entry and setup of course and program outcomes are accomplished through parsing Microsoft Word formatted course syllabi and program annual report forms. Courses outcomes are satisfied through embedded questions and exercises during the academic term. At the end of the academic term, the instructor completes a Faculty Course Assessment Report (FCAR). In order to ensure continual improvement as part of the assessment process, adjustments are made at the course level to 
improve upon the instructional strategies employed for each class and noted in the individual Searchlight Faculty FCAR reports.

\section{Searchlight Performance Assessment Framework}

SearchLight Performance Assessment is a very flexible performance assessment engine designed to help educational institutions effectively utilize data to drive decision-making. The software provides educational institutions with an assessment tool that will allow them to enter, generate, and analyze course or program based performance rubrics. While the software is optimized for the collection and analyses of information necessary for accreditation processes, it is also flexible enough to be tailored to the needs of nearly any entity. This assessment tool is intended to be standalone and requires no additional equipment or software.

Formative and summative assessment tools will be used to help faculty evaluate how students are meeting the learning goals in the program. The PAF facilitates the process of performing both formative and summative assessment. Appropriate assessment instruments are created and refined through the software by aggregating formative assessments at the course level in order to improve activities and processes that ensure attainment of program goals. Data collected each year are used for annual reports and to guide long term planning. Summative evaluations also aid in the achievement of program goals and objectives.

SearchLight ${ }^{\mathrm{TM}}$ also offers the means to perform program assessments through both direct and indirect means. Direct assessments are appropriate for determining the effectiveness of in-class teaching practices and course outcomes. Indirect assessments through various survey instruments are appropriate for determining best-practices for STEM pedagogy and course outcomes. Both direct and indirect methods can be mapped to program outcomes to ensure program objectives are being met. The PAF is also capable of tracking changes to courses throughout the duration of the program.

Features of the Performance Assessment Framework Searchlight ${ }^{\mathrm{TM}}$ is a web-based performance assessment tool that offers an electronic rubric-driven assessment entry method that models the assessment process closely; is easy to deploy, requires a short set-up time and has graphics-driven data-mining capabilities. The software offers additional features which include:

- Multiple Course Assessment Methods

- Direct and Indirect Assessments

- Formative and Summative Assessments

- The ability to Import Data

- MSWord, Excel, CMS e.g. Bb, SIS

- syllabi automatically create course outcomes

- Flexible Assessment Metrics

- Program outcomes with associated performance criteria-department

- Course outcomes and course instruments, mapped to multiple course outcomes 
- Multiple Assessment Entry Methods

- Gradebook or Rubrics

- Performance Review

- Aggregate by data tables and graphs

- Drill down - program outcomes - pc - courses, surveys

- Course Progress Tracker - store data \& track progress over different periods

- Automatic Reporting using Faculty Course Assessment Reports (FCARS)

- Training \& Technical Support

\section{Getting Started using the Performance Assessment Software}

The performance assessment software has four main functions - allows data importation, creating performance assessment metrics, implementing performance assessments and generating performance reviews and reports.

Figure 1 shows a typical front-page in the performance assessment software indicating courses being taught and assessments to date.

Figure 1: Faculty Page in the PAF

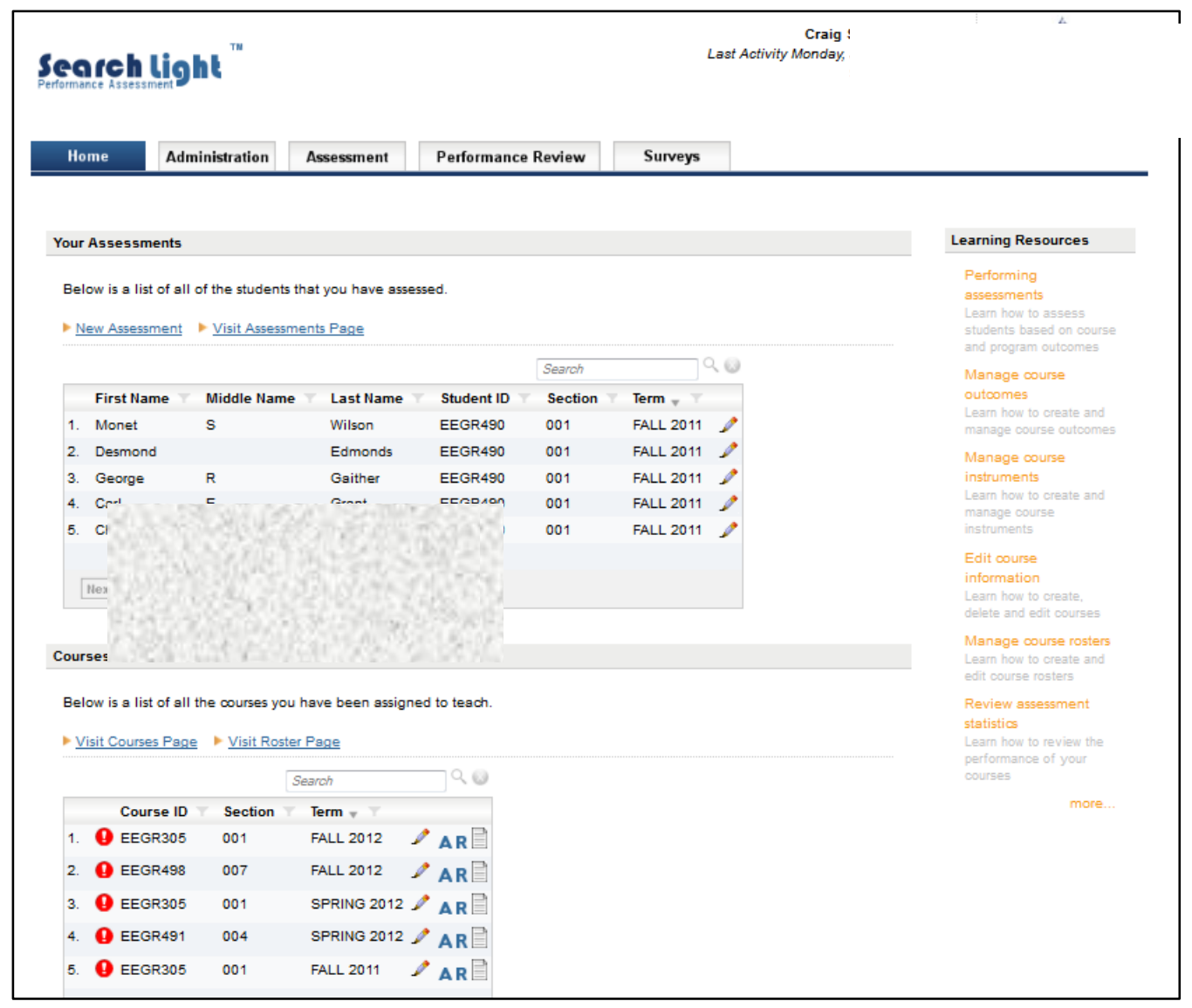




\section{Program Outcomes and Performance Criteria}

Program outcomes $(a-k)$ and associated performance criteria are based on ABET accreditation guidelines. Performance criteria are linked to program outcomes and are specific measures of the program outcomes being assessed. Table 1 represents program learning outcomes that are evaluated based on a 6-year accreditation cycle. These program outcomes and associated performance criteria (Figure 2) are imported into the performance assessment framework and are linked to courses and specific course outcomes.

Table 1: Program Learning Outcomes $(\boldsymbol{a}-\boldsymbol{k})$ and 6-year Assessment Cycle

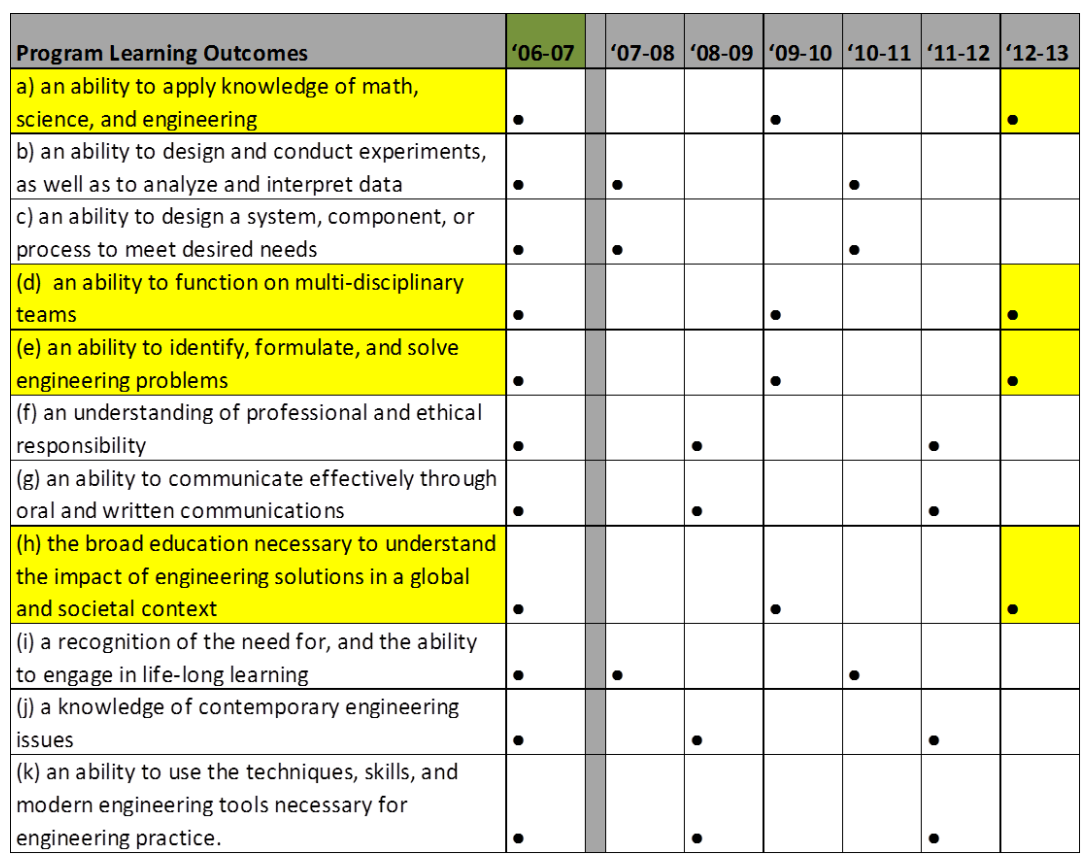

Figure 2: Sample Program Outcomes and Associated Performance Criteria

a) an ability to apply knowledge of mathematics, science, and engineering

1. Identifies mathematical and physical concepts needed to solve the problem $(\mathrm{M}, \mathrm{S})$

2. Explains the role of mathematics as a tool for modeling systems and processes. $(\mathrm{M})$

3. Expresses problem in terms of mathematical and scientific statements (M, S)

4. Uses fundamental engineering principles to solve engineering related problems (E)

b) an ability to design and conduct experiments as well as analyze and interpret results

1. Develops a hypothesis and a plan (experimental method) to evaluate it using engineering principles and practice. (D)

2. Collects data using software and electronic test and measurement equipment (C)

3. Analyzes results and components of the design using engineering models. (A)

4. Explains experimental results as they relate to theoretical results. (I) 


\section{Creating Performance Assessment Metrics and Mapping Outcomes}

The performance assessment framework permits you to assess students through two types of metrics, program outcomes - defined by their performance criteria, and course outcomes assessed through course instruments. While program outcomes are typically established by department heads, course outcomes are ideally created by instructors. Course Instruments are specific metrics, such as a question on an exam or homework, which satisfies one or more course outcomes. Outcomes and performance criteria are mapped to the courses using the matric mode as shown in Figure 3.

Figure 3: Assigning Outcomes to Courses
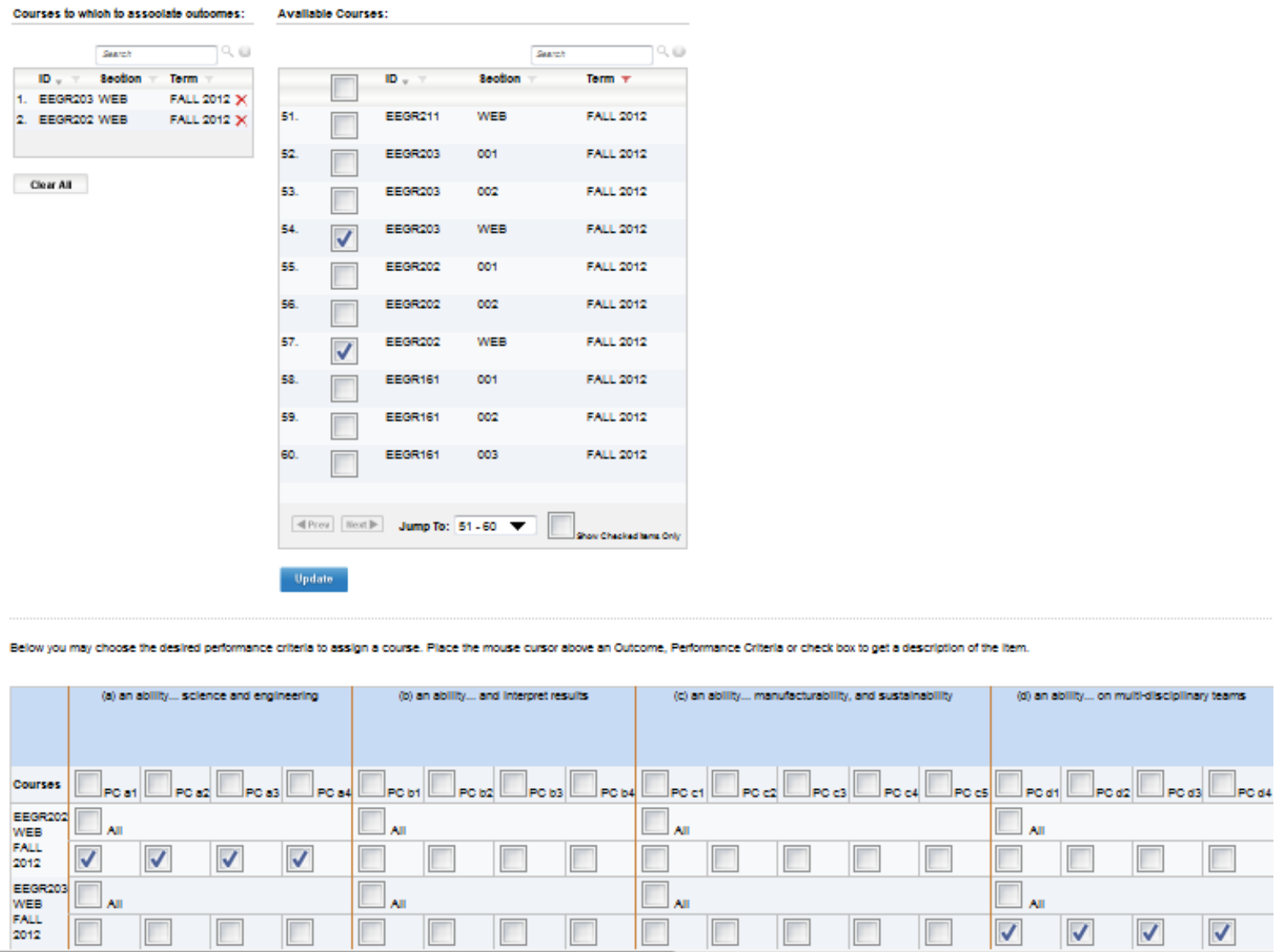

For example, the following course outcome: "Write steady state solution equations and analyze transmission line circuits operating in the steady state mode,"'- would map to the program outcome: (a) "an ability to apply knowledge of mathematics science and engineering." Another course outcome example: "Students will be expected to demonstrate their ability to apply logic in solving the charge neutrality equation, which is a transcendental function" would map to program outcomes [a, e] - (a) "an ability to apply knowledge of mathematics 
science and engineering;" and (e) "an ability to identify, formulate, and solve engineering problems."

Another example of course outcome: "Students will be expected to demonstrate their ability to cooperate with others, share information with others, and demonstrate their ability to take a leadership role in support of the team's goals while conducting Lab experiments." - would map to program outcomes $[\mathrm{b}, \mathrm{d}, \mathrm{g}]-(\boldsymbol{b})$ "an ability to design and conduct experiments, as well as to analyze and interpret data;" (d) "an ability to function on multi-disciplinary teams;" ( $(\mathbf{g})$ "an ability to communicate effectively through oral and written communications." Furthermore an instrument: "Final Project, Question 1" can be created that satisfies one or more of the performance criteria under program outcome $(\boldsymbol{a})$, such as "Uses fundamental engineering principles to solve engineering related problems."

\section{Course Laboratory Outcomes Mapping Example}

Students enrolled in the online ECE courses have to first complete introductory training laboratory experiments that familiarize them with the various features of the technology being used. Detailed discussions on how our university developed various design projects and laboratory experiments using various forms of online technology has been discussed in detail in our previous papers ${ }^{6,7}$. One question that has consistently been raised is whether students have acquired the laboratory skills commensurate with satisfying our program outcomes.

The following illustration (Figure 4) shows a section of an RC filter laboratory experiment where students are given instructions on how to build and test both High Pass and Low Pass filter circuits with a specified cut-off frequency. We were able to evaluate and compare the performance of the students using our performance assessment framework by entering the course objectives mapped to the program objectives. Figure 5 shows the online version of the $\mathrm{RC}$ filter lab experiment.

Figure 4: Sample RC lab given to all students enrolled in the laboratory course

\section{EEGR 203} Dr. XXXXXXX

\section{Lab 7 - Low Pass and High Pass Filter Circuit Design}

The characteristics of the low pass and high pass filter circuits were discussed in the classroom. Please refer to your class notes for more information related to filter circuits. This laboratory experiment will be conducted in the regular laboratory room using the Agilent XSeries Oscilloscopes with integrated Function Generators.

Part I- Low Pass Filter: Design, build and test the low pass filter circuit shown in Figure\#1a 
such that the cutoff frequency is about $5 \mathrm{KHz}$. Build the circuit and use the Agilent X-Series Oscilloscopes with integrated Function Generators to test the response of your circuit. Assume that Vin is a 1 Volt peak to peak sine wave.

You need to be able to answer the following questions after completing the experiment:

- What do you expect the output voltage Vout to be when you reach the cut-off frequency? Why?

- What happens to Vout after you pass the cut-off frequency? Why?

- Plot your data on Microsoft Excel using Vout versus frequency and (Vout/Vin) versus frequency and prove that the cut-off frequency that you have designed matches the one that is obtained after you build the circuit.

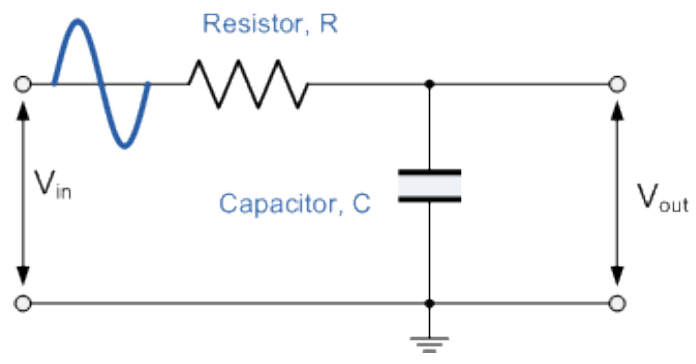

Figure 1a: Low Pass Filter

Part II- High Pass Filter: Design, build and test the high pass filter circuit shown in Figure\#1b such that the cutoff frequency is about $5 \mathrm{KHz}$. Build the circuit and use the Agilent $\mathrm{X}$-Series Oscilloscopes with integrated Function Generators to test the response of your circuit. Assume that Vin is a 1 Volt peak to peak sine wave.

You need to be able to answer the following questions after completing the experiment:

- What do you expect the output voltage Vout to be when you reach the cut-off frequency? Why?

- What happens to Vout after you pass the cut-off frequency? Why?

- Plot your data on Microsoft Excel using Vout versus frequency and (Vout/Vin) versus frequency and prove that the cut-off frequency that you have designed matches the one that is obtained after you build the circuit.

Figure 5: RC Filter Lab given to the students enrolled in the online course 


\section{Lab 7-WEB - Low Pass and High Pass filter circuit design}

The characteristics of the low pass and high pass filter circuits were discussed in the classroom. Please refer to your class notes for more information related to filter circuits. This laboratory experiment will be conducted completely online using the internet to connect to the Agilent XSeries Oscilloscopes with integrated Function Generators remotely. The goal of this experiment is to determine the type of filter that is attached to the instrumentation board after taking measurements and analyzing the data that is collected.

Part I- Determine the type of filter circuit connected to the laboratory equipment

The Agilent X-Series Oscilloscopes with integrated Function Generators located in the laboratory is connected to an unknown RC filter circuit as shown in Figure 2a. Assume that Vin is a 1 Volt peak to peak sine wave. Connect to the oscilloscope remotely and take measurements of Vout versus frequency by varying the frequency from $100 \mathrm{~Hz}$ up to $10 \mathrm{KHz}$.

You need to be able to answer the following questions after completing the experiment:

- What type of filter circuit do you think the circuit in the Black Box represent?

- Is it a High Pass or Low Pass filter? Why?

- What is your estimate for the cut-off frequency? Why?

- Plot your data on Microsoft Excel using Vout versus frequency and (Vout/Vin) versus frequency and prove that response of the filter circuit behaves as expected.

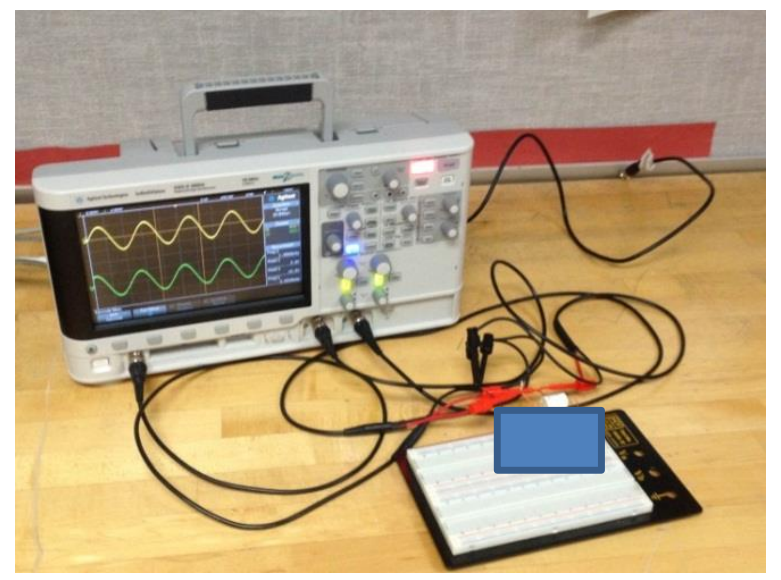


Figure 2a: Unknown Filter circuit connected to Agilent Equipment

Part II- Design, build and test a new filter circuit that has the same cutoff frequency as the circuit tested in Part I. Use your Mobile Studio IOBoard ${ }^{\mathrm{TM}}$, to test your filter circuit. Assume that Vin is a 1 Volt peak to peak sine wave. Choose the appropriate values for $\mathrm{R}$ and $\mathrm{C}$ such that the cut-off frequency is as close as possible to the estimated value obtained from part I of the laboratory experiment.

You need to be able to answer the following questions after completing the experiment:

- What do you expect the output voltage Vout to be when you reach the cut-off frequency? Why? Plot your data on Microsoft Excel using Vout versus frequency, and (Vout/Vin) versus frequency.

- How does the response of the new filter circuit compare to that of the original circuit given in Part I?

- Please discuss your results in detail by comparing the cut-off frequencies of the two filter circuits given in Part I and Part II.

Part III- Repeat the experiments in Part I and Part II after the circuit connected to the Agilent X-

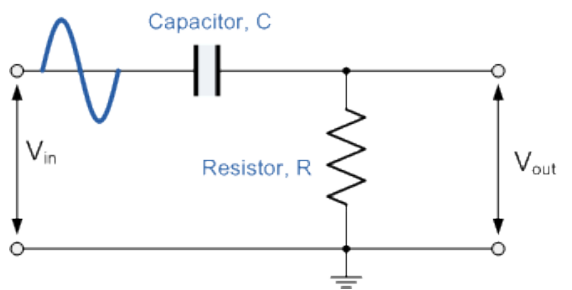

Series Oscilloscopes has been changed by the instructor.

We were able to evaluate and compare the performance of the students using our performance assessment framework by entering the course objectives mapped to the program objectives as listed below. The corresponding program outcome is shown in square brackets.

\section{EEGR203 Expected Course Outcomes}

- Students will be expected to demonstrate their ability to apply basic circuit analysis techniques to design and conduct laboratory experiments, and to also be able to analyze and interpret the results they obtain. [b] 
- Students will be expected to demonstrate their ability to cooperate and share information with others, while conducting laboratory experiments. [d]

- Students will be expected to demonstrate their ability to communicate effectively by writing weekly laboratory reports [g]

- Students will be expected to demonstrate their ability to use modern hardware and software engineering tools to complete their weekly laboratory experiments. [k]

\section{Relationship of EEGR202/203 Course Outcomes to Program Outcomes}

(b) An ability to design (D) and conduct (C) experiments as well as analyze (A) and Interpret (I) results

(d) An ability to function on multi-disciplinary teams

(g) An ability to communicate effectively through oral and written (W) communications

(k) An ability to use the techniques, skills, and modern engineering tools necessary for Engineering practice

\section{Performance Assessment}

Once courses and program or course outcomes have been mapped within the performance assessment framework, individual student assessment can be generated to evaluate course or program effectiveness. Performance reviews can be assessed by semester or by course and the data aggregated into data tables and/or graphs. Performance reviews can also be compiled based on specified outcomes and data drill-down depicted at the performance criteria level to accurately evaluate each element of a program outcome. The performance assessment reviews can be evaluated using the grade-book method, downloadable in excel format, or the rubric format based on a Likert scale. Performance assessment reports captures the results of the assessments which are generated based on results for individual courses, specific program or course outcomes or aggregated by courses or outcomes for a semester.

\section{Course/Program Performance Assessment Review}

Performance assessment reviews have been implemented for the past 6 years, using the performance assessment framework. The assessment data collected are analyzed and shared with faculty for review. Faculty then provides strategies for improving the course and documents those changes in a faculty course assessment report (FCAR).

\section{Faculty Course Assessment Report (FCAR)}

The faculty course assessment report (FCAR) is utilized by Faculty to summarize course level observations and actions. The FCAR (Figure 6) can be automatically generated for any course and serves as a record for all qualitative and quantitative information for the course and related outcomes that are assessed. This report contains a breakdown of how well the course satisfied its assigned outcomes, as well as information on the modifications made to the course, the student 
feedback, reflections, proposed actions, and grade distribution. Changes to any course can be tracked via the FCAR from one academic term to the next.

Figure 6: Sample Faculty Course Assessment Report

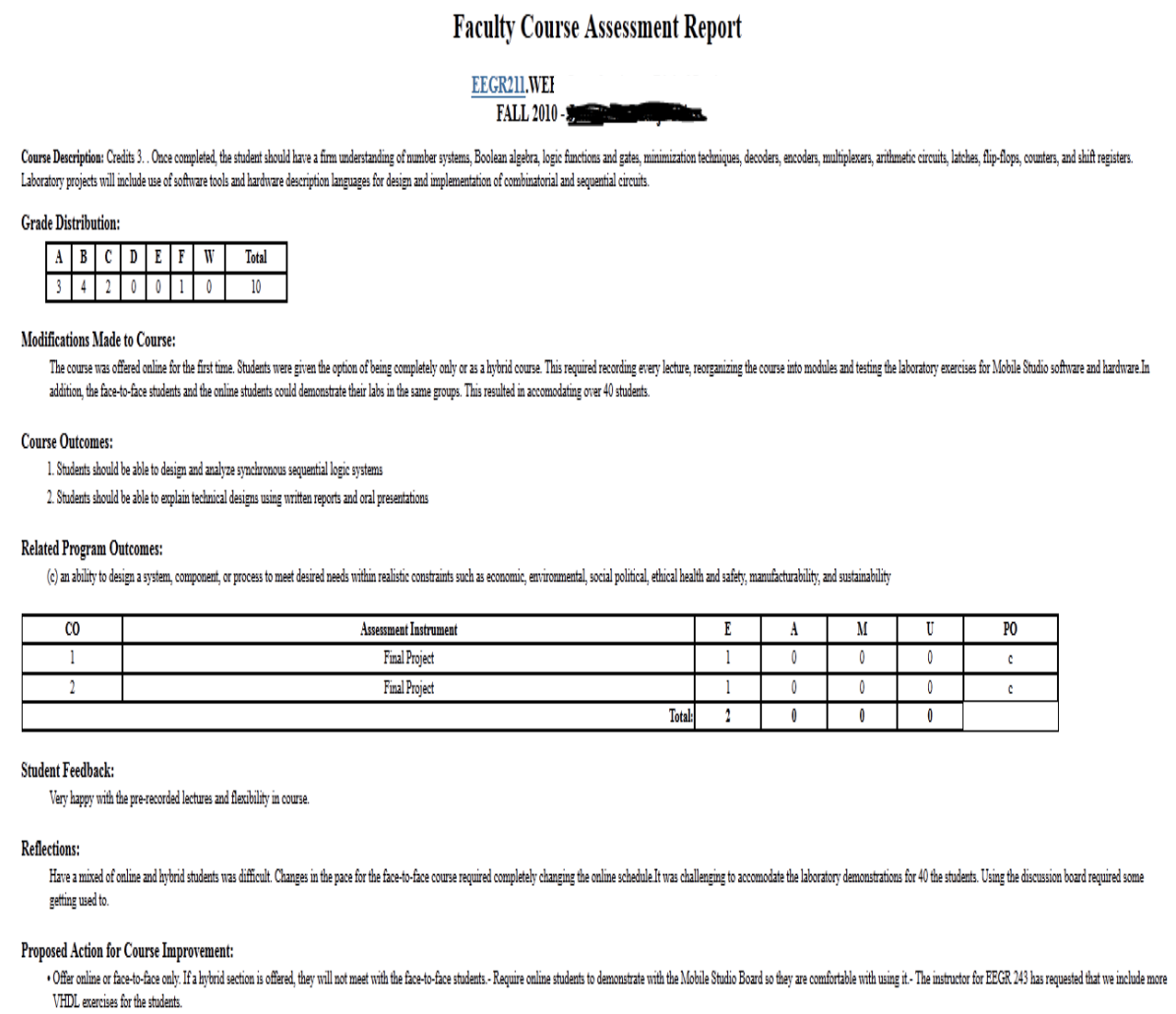

\section{Performance Assessment Reports}

Performance review results collected and analyzed over the 2-year period 2009-2011 are presented and discussed below. Each academic year, the outcome measures scheduled for assessment are determined based on the 6-year ABET accreditation cycle. The measures scheduled for assessment during the 2009-10 cycle included outcomes $-\boldsymbol{a}, \boldsymbol{d}, \boldsymbol{e}$, and $\boldsymbol{h}$, while outcomes - b, $\boldsymbol{c}$ and $\boldsymbol{i}$ were measured during the 2010-11 cycle. The meeting to solicit faculty input based on the assessment cycle occurs at the beginning and end of the each academic year/term.

\section{9-10 Assessment Cycle}

In the annual performance review any "unacceptable" outcome evaluation above the targeted threshold of $25 \%$ can result in an automatic departmental course review and subsequent modification. From direct measurements there appeared to be no major shortcomings in any of the targeted areas during the 2009-10 assessment cycle (Figures 7. and 8). As a matter of 
continual improvement, however, adjustments were made at the course level to improve upon the instructional strategies employed for each class and noted in the individual FCAR reports. In addition, Faculty was asked to review ways in which outcome (a) "an ability to apply knowledge of mathematics, science and engineering can be improved," and outcome (e) "an ability to identify, formulate, and solve engineering problems." This was necessary since both outcome (a) and outcome $(\boldsymbol{e})$ were showing relatively high "unacceptable" ratings between the fall and spring semesters of the assessment cycle.

Figure 7: Comparison of Fall 2009 Outcomes (a, d, e and h)

\begin{tabular}{|c|c|c|c|c|}
\hline Outcomes & 1: Unacceptable & 2: Needs Improvement & W: Meets Expectation & 4: Exceeds Expectation \\
\hline (a) an ability to apply knowledge of mathematics science and engineering & $19(19.79 \%)$ & $25(26.04 \%)$ & $29(30.21 \%)$ & $23(23.9696)$ \\
\hline (d) an ability to function on multi-disciplinary teams & $5(4.10 \%)$ & $24(19.67 \%)$ & $34(27.87 \%)$ & $59(48.36 \%)$ \\
\hline (e) an ability to identify, formulate, and solve engineering problems & $4(2.17 \%)$ & $25(13.59 \%)$ & $56(30.43 \%)$ & $99(53.80 \%)$ \\
\hline $\begin{array}{l}\text { (h) the broad education necessary to understand the impact of engineering } \\
\text { solutionsin a global, economic, environmental, and societal contert }\end{array}$ & $0(0.00 \%)$ & $5(14.71 \%)$ & $5(14.71 \%)$ & $24(70.59 \%)$ \\
\hline Grand Total: & 28 & 79 & 124 & 205 \\
\hline
\end{tabular}

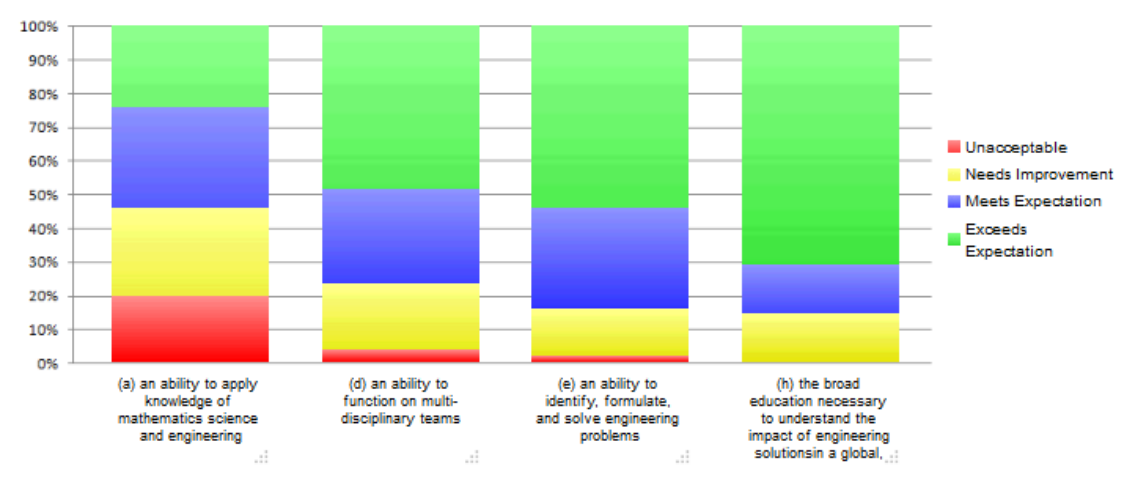

Figure 8: Comparison of Spring 2010 Outcomes (a, $\boldsymbol{d}, \boldsymbol{e}$ and $\boldsymbol{h}$ )

\begin{tabular}{|l|c|c|c|c|}
\hline $\begin{array}{l}\text { Outcomes } \\
\text { (a) an ability to apply knowledge of mathematics science and engineering }\end{array}$ & $\begin{array}{l}\text { 1: Unacceptable } \\
\text { 2: Needs Improvement }\end{array}$ & $\begin{array}{c}\text { 1: Meets Expectation } \\
\text { 4: Exceeds Expectation }\end{array}$ & $142(36.22 \%)$ \\
\hline (d) an ability to function on multi-disciplinary teams & $0(0.00 \%)$ & $2(2.90 \%)$ & $38(55.07 \%)$ & $29(42.03 \%)$ \\
\hline (e) an ability to identify, formulate, and solve engineering problems & $23(9.58 \%)$ & $20(8.33 \%)$ & $102(42.50 \%)$ & $95(39.58 \%)$ \\
\hline $\begin{array}{l}\text { (a) the broad education necessary to understand the impact of engineering } \\
\text { solutionsin a global, economic, environmental, and societal context }\end{array}$ & $0(0.00 \%)$ & $2(9.09 \%)$ & $10(45.45 \%)$ & $10(45.45 \%)$ \\
\hline Grand Total: & 48 & 120 & 279 & 276 \\
\hline
\end{tabular}

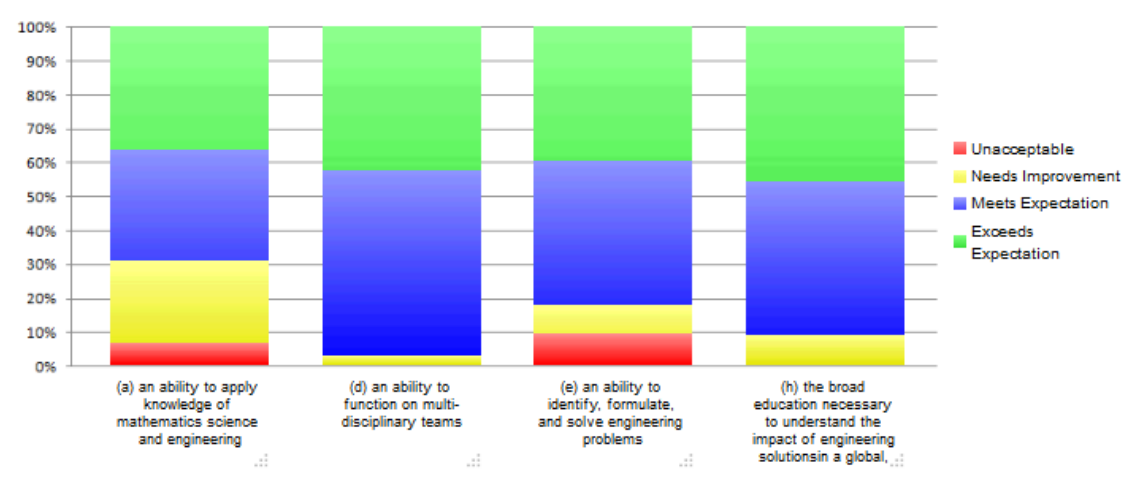




\section{Drill-down Analysis of Assessment Cycle 2009-10 - Outcomes (a, d, e and h)}

A closer examination of outcomes (a) and (e) shows the performance criteria which were assessed (Figure 9 and 10). While outcome (a) recorded an improvement from the fall 2009 to spring 2010 period, outcome $(\boldsymbol{e})$ recorded an increase in the "unacceptable" rating and prompted a closer examination.

Examination of the performance criteria associated with outcome (a) illustrates the need for students to better appreciate the connection between math and the engineering process. Examination of the performance criteria associated with outcome $(\boldsymbol{e})$, suggest students are primarily having difficulty with identifying various approaches to solving problems and applying engineering concepts to solving problems.

Typically, such observations are discussed at the end of semester Faculty meetings and strategies suggested and implemented during the succeeding academic term.

Figure 9: Performance Criteria for Outcome (a) and (e) - Fall 2009

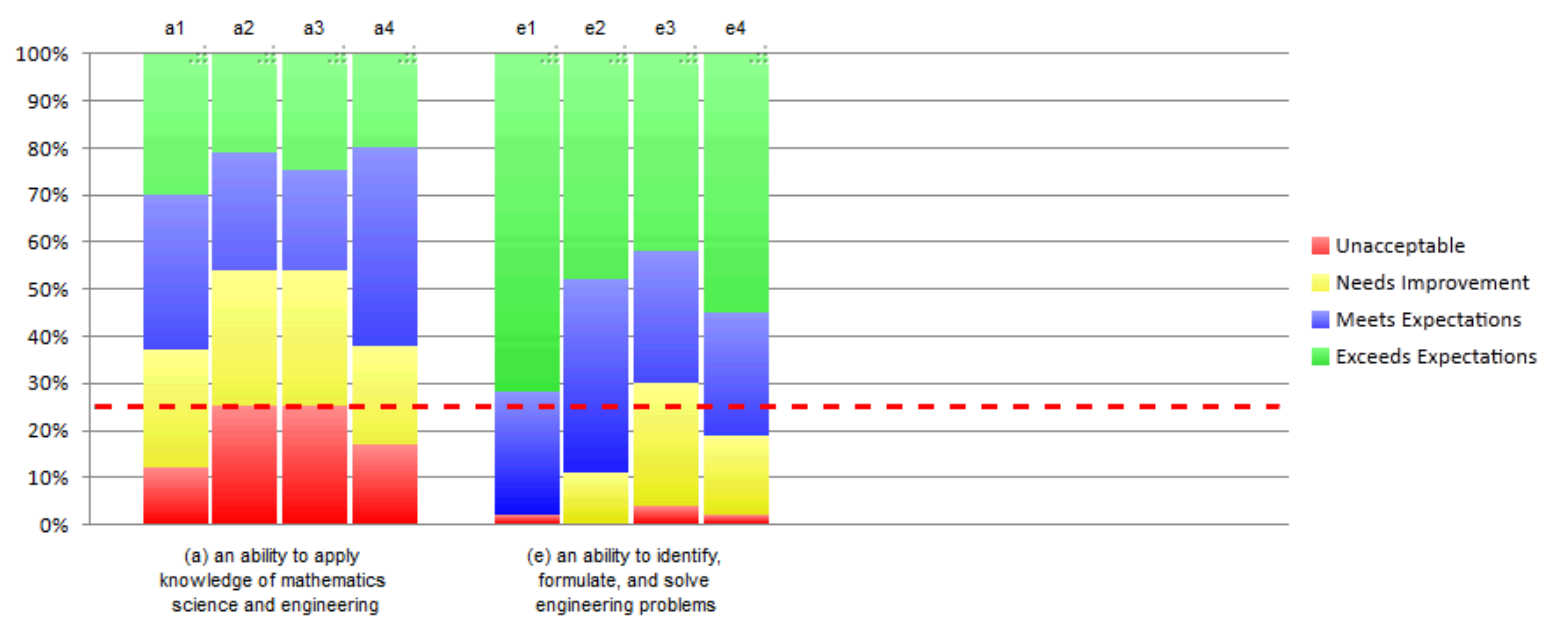

a1. Identifies mathematical and physical concepts needed to solve the problem( $M, S)$ (knowledge)

a2. Explains the role of mathematics as a tool for modeling systems and processes(M)(comprehension)

a3. Expresses problem in terms of mathematical and scientific statements( $M, S)$ (comprehension)

a4. Uses fundamental engineering principles to solve engineering related problems(E)(application)

e1. Recognizes and identifies the information that is needed to solve engineering problems(I) (knowledge and comprehension)

e2. Identifies various approaches to solving the problem (F)(comprehension)

e3. Outlines a solution to the problem using engineering concepts. (S)(analysis)

e4. Validates the problem solution (S)(evaluation 
Figure 10: Performance Criteria for Outcomes (a) and (e) - Spring 2010

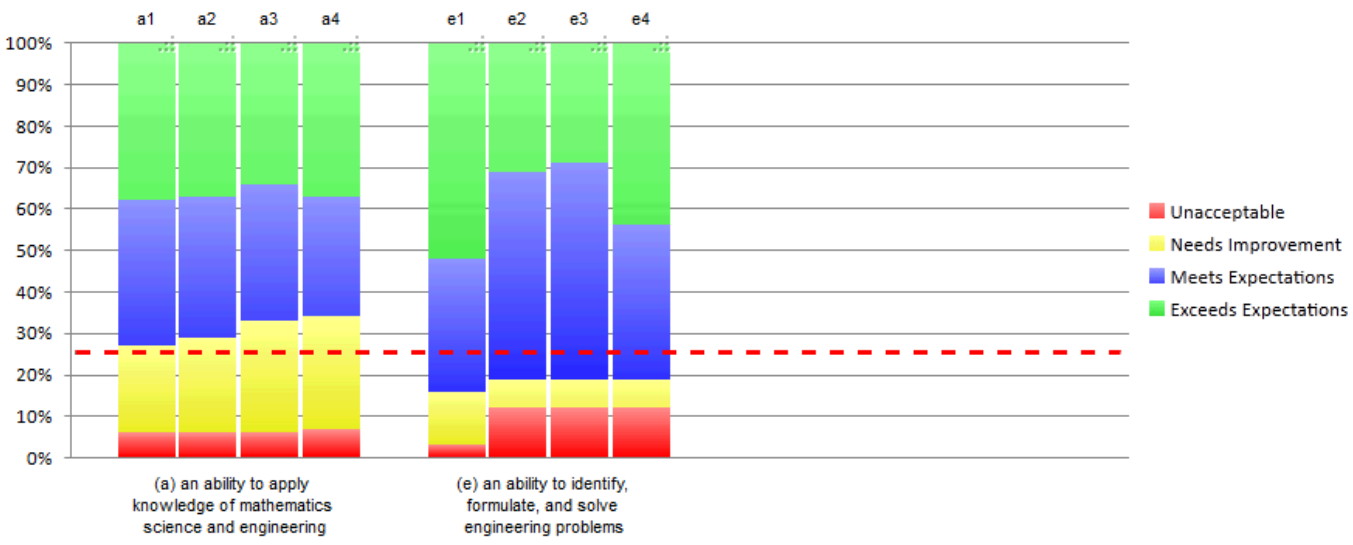

\footnotetext{
a1. Identifies mathematical and physical concepts needed to solve the problem( $M, S)$ (knowledge)

a2. Explains the role of mathematics as a tool for modeling systems and processes(M)(comprehension)

a3. Expresses problem in terms of mathematical and scientific statements $(M, S)$ (comprehension)

a4. Uses fundamental engineering principles to solve engineering related problems(E)(application)

e1. Recognizes and identifies the information that is needed to solve engineering problems (I) (knowledge and comprehension)

e2. Identifies various approaches to solving the problem (F)(comprehension)

e3. Outlines a solution to the problem using engineering concepts. (S)(analysis)
}

\section{0-11 Assessment Cycle - Outcomes (b, c and i)}

The measures scheduled for assessment during the 2010-2011 cycle included outcomes - $\boldsymbol{b}, \boldsymbol{c}$, and $\boldsymbol{i}$ (Figure 11). Outcome (i) raised concerns since the combined "unacceptable/needs improvement" measure was at $30 \%$. Subsequently, Faculty was asked to think about ways in which outcome $(i)$ - a recognition of the need for, and the ability to engage in life-long learning can be improved. The following academic term (Spring 2011) recorded a significant improvement in all outcomes (Figure 12).

Figure 11: Fall 2010 Outcomes (b, $\boldsymbol{c}$, and $\boldsymbol{i})$

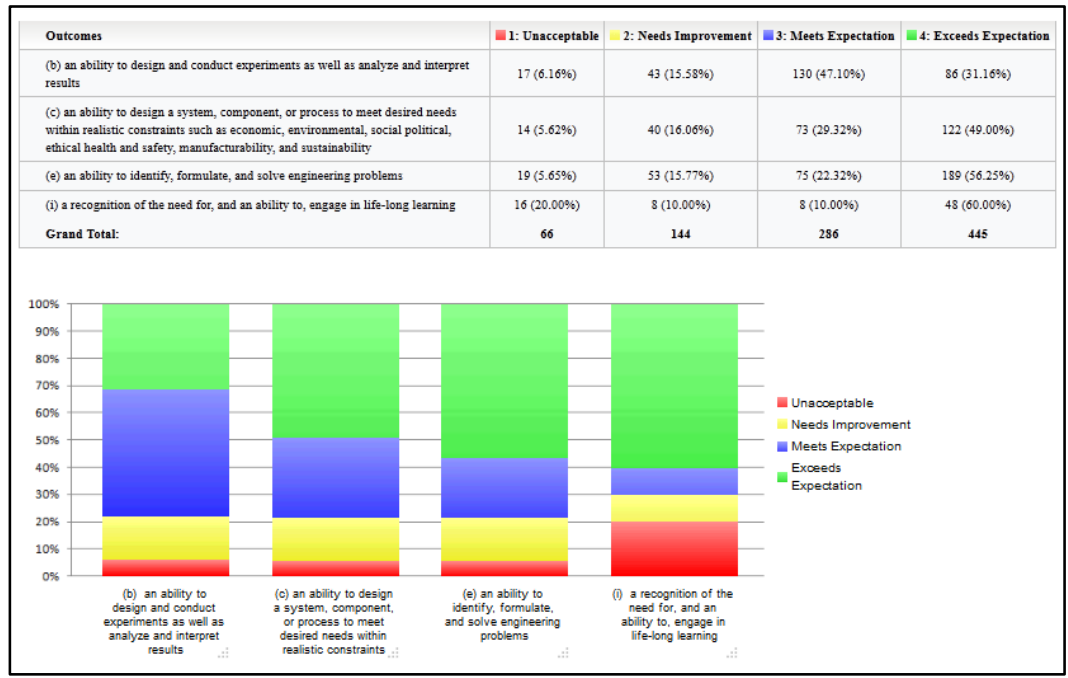


Figure 12: Spring 2011 - Outcomes (b, $\boldsymbol{c}$ and $\boldsymbol{i})$

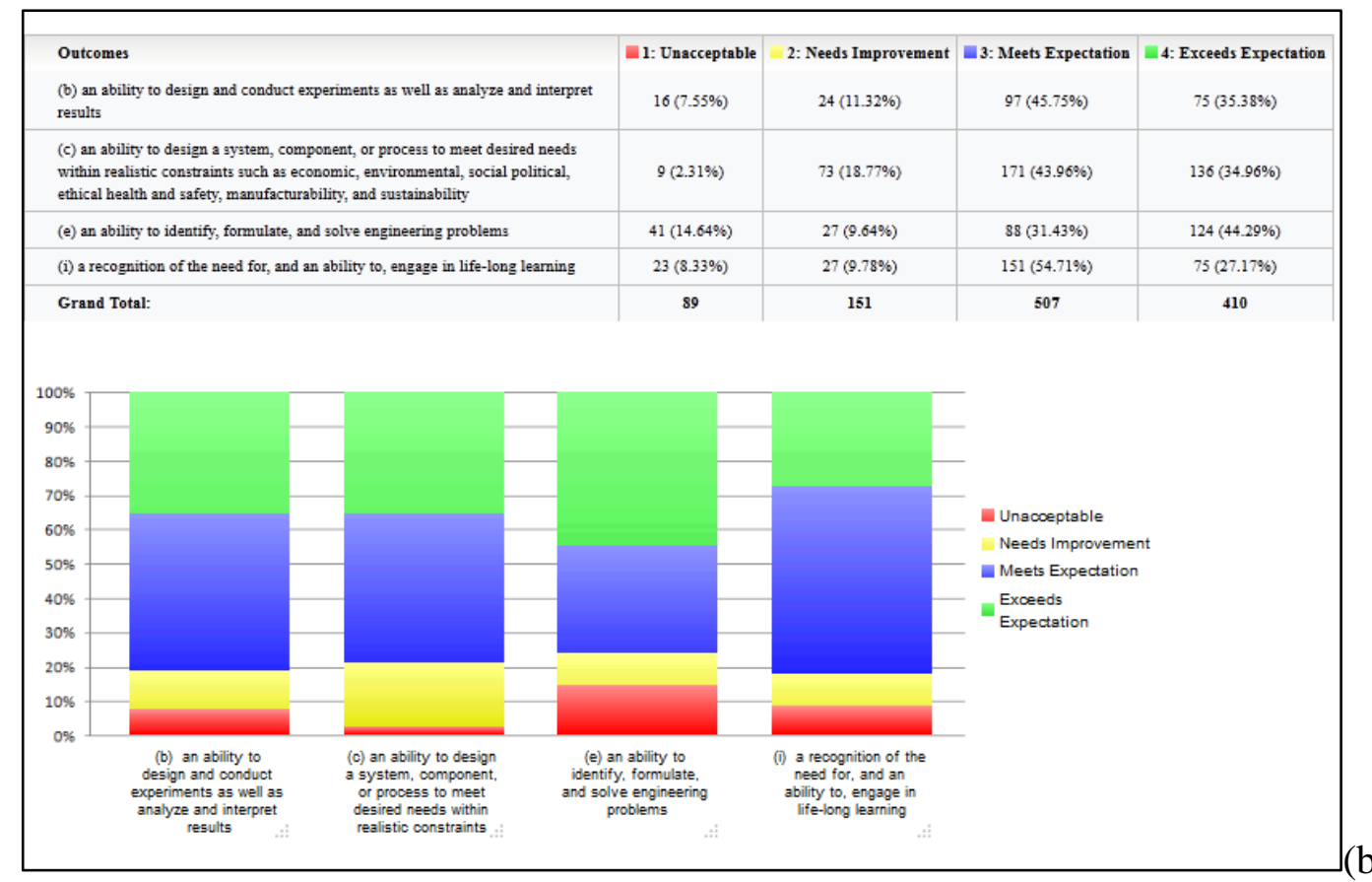

\section{Performance Review - Continual Improvement}

As one example, it was found that there was a need for students to have both better professional development and education plans. In both cases, specific course revisions and teaching strategies adopted and employed with the help of the performance assessment framework. Improvements in both areas were measured and sustained within one academic term.

During academic term Fall 2010, a closer review of outcome (i), Figure 13 shows the performance criteria measured. This illustrates that students need to have a better appreciation of the need for both a professional development plan and an education plan, which in turn will increase their awareness of the need to participate in student professional organizations and attend conferences, workshop and other similar activities. This observation was discussed and strategies implemented during the Spring 2011 semester by adding an extra module in EEGR400 - Professional Practice - to specifically address the observed student deficiencies.

It should also be noted that outcome $(\boldsymbol{e})$ although not scheduled during the 2010-2011 cycle was included as a follow-up to the $2009-2010$ cycle. In 2009-2010 cycle outcome $(\boldsymbol{e})$ - "an ability to identify, formulate, and solve engineering problems" - recorded an increase in the "unacceptable/needs improvement". Although there was a marked improvement in outcome (e) during the Fall 2010 academic term, outcome (e) continued to present challenges (Figure 14). 
Figure 13: Fall 2010 - Performance Criteria $\boldsymbol{i}$ and $\boldsymbol{e}$

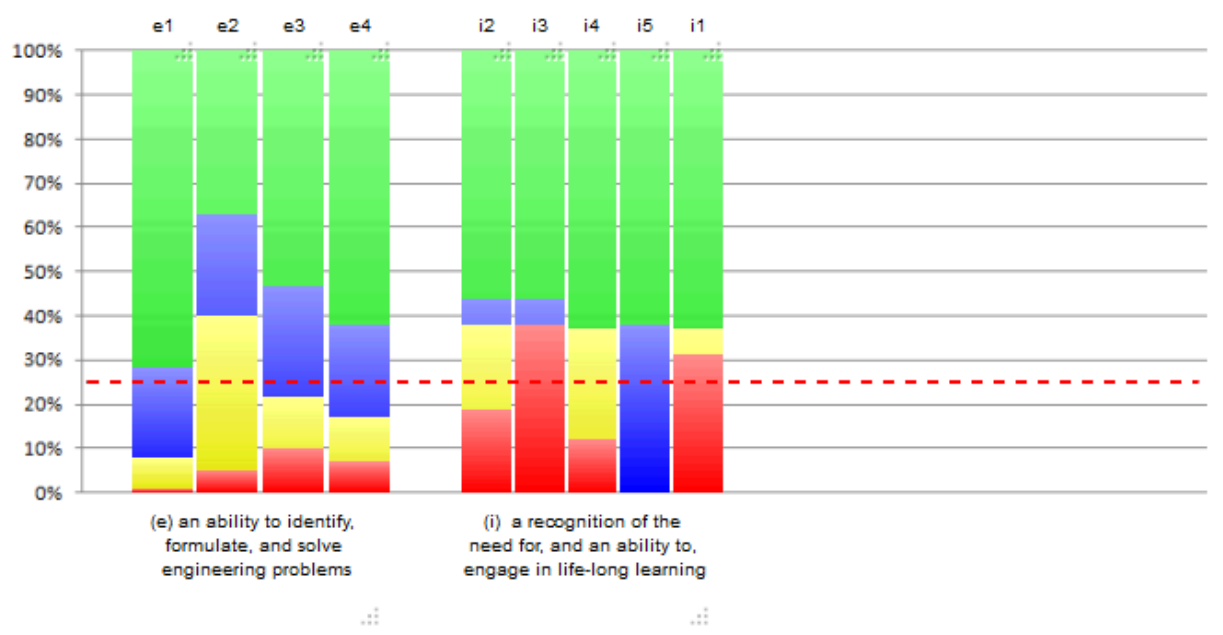

Unacceptable

Needs Improvement

Meets Expectation

Exceeds Expectation

e1. Recognizes and identifies the information that is needed to solve engineering problems(l) (knowledge and comprehension)

e2. Identifies various approaches to solving the problem (F)(comprehension)

e3. Outlines a solution to the problem using engineering concepts. (S)(analysis)

e4. Validates the problem solution (S)(evaluation)

i2. Develops a professional development plan(synthesis)

i3. Chooses to be involved in student professional organizations(receiving)

i4. Recognizes the need to enroll in workshops, seminars, conferences and/or short courses, after graduation

i5. Applies knowledge of new information sources (professional journals, etc.) to write a technical report(application)

i1. Develops an educational plan(synthesis)

\section{Figure 14: Spring 2011 - Performance Criteria $\boldsymbol{i}$ and $\boldsymbol{e}$}

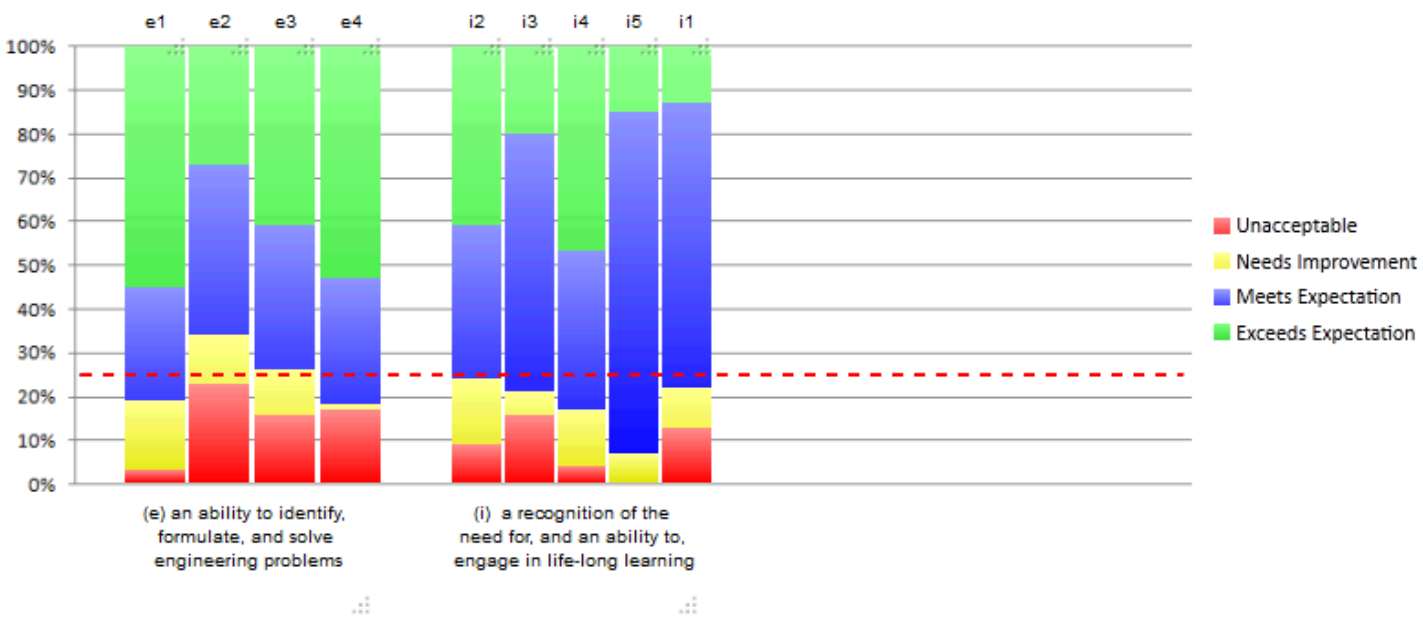

\footnotetext{
e1. Recognizes and identifies the information that is needed to solve engineering problems $(l)$ (knowledge and comprehension)

e2. Identifies various approaches to solving the problem (F)(comprehension)

e3. Outlines a solution to the problem using engineering concepts. (S)(analysis)

e4. Validates the problem solution (S)(evaluation)

i2. Develops a professional development plan(synthesis)

i3. Chooses to be involved in student professional organizations(receiving)

i4. Recognizes the need to enroll in workshops, seminars, conferences and/or short courses, after graduation

i5. Applies knowledge of new information sources (professional journals, etc.) to write a technical report(application)

i1. Develops an educational plan(synthesis)
} 


\section{Faculty and Administrative Impressions}

Over the years spanning the evolution and improvement of this tool, the rubric entry approach is heavily favored over the grade book entry approach by faculty. This came as a surprise owing to the fact the grade book entry method more closely mimics the conventional approach to submitting grades. Sample faculty comments were:

"it (the rubric method) feels just like using a paper rubric but the quantitative results are automatically tabulated for you"

"Teaching an online course is a lot of work. This tool allows me to do a good job of assessing my course outcomes without adding that much of a burden"

"I like being able to review my FCAR so that I can track and remember what I was thinking and what I was planning to do from semester to semester"

Program level administrators appreciate the ease in which it takes to setup from existing documents and maps. Typical setup times were under one day to get all objectives and outcomes set up. Comments from administrative personnel include:

"It's nice to be able to map course outcomes to program outcomes by extracting the information directly from the syllabi"

"This software lets me accomplish what used to take days in a matter of keystrokes we can now almost do our analysis in real time"

"I have never been able to drill down from program level statistics to identify the good and bad performing course sections. Asymmetries in teaching strategies can easily and objectively be identified for corrective action and student fairness"

Drawbacks were mainly from unimplemented features such as the inability to determine individual student performance metrics. Also time series reporting over periods other than term to term within one academic year was found to be in need of improvement. Another drawback is that it still requires the updating of course to program level mappings to be copied or setup from semester to semester. Some administrators would like for the mapping to occur automatically alleviating the need for a dedicated assessment/IT specialist.

\section{Summary}

In summary, our performance assessment framework facilitates an easier and data-driven effective analysis of both program and course outcomes especially as applied to courses offered in an online environment. The application allows a hierarchical exploration of program and course level outcomes. Subsequently, this framework facilitates the process of performing both formative and summative assessments using both direct and indirect measures for our Electrical Engineering program, as well as other programs in other disciplines. The ability to map these 
outcomes allows the instructor to focus on improving the course, while the program director can focus on a process that supports continual program improvement. The ability to offer a tool to accomplish both visual and learning analytics of online performance trends has proven to be an extremely useful capability for maintaining a viable enhanced learning environment as our online program evolves.

\section{References}

1. E. Allen, J. Seaman, "Going the Distance: Online Education in the United States, 2011", The Sloan Consortium, published November 2011.

2. P. Baepler, and C. J. Murdoch, "Academic analytics and data mining in higher education". International Journal for the Scholarship of Teaching and Learning, 4 (2), July 2010.

3. McGourty, Jack, Kevin Scoles, and Stephen Thorpe. "Web-based course evaluation: comparing the experience at two universities." Frontiers in Education, 2002. FIE 2002. 32nd Annual. Vol. 1. IEEE, 2002.

4. Buzzetto-More, Nicole A., and Ayodele Julius Alade. "Best practices in e-assessment." Journal of Information Technology Education 5.1 (2006): 251-269.

5. Williams, J. M. "Evaluating What Students Know: Using the RosE Portfolio System for Institutional and Program Outcomes Assessment." Professional Communication, IEEE Transactions on 53.1 2010: 46-57.

6. Y. Astatke, C. Scott, J. Ladeji-Osias, "Electric Circuits Online- Towards a completely Online Electrical Engineering Curriculum," 2011 American Society of Engineering Education (ASEE) Annual Conference, Vancouver, British Columbia, Canada, June 26-29, 2011.

7. Y. Astatke, J. Ladeji-Osias, C. J. Scott, K. Abimbola, and K. Conner, "Developing and Teaching Sophomore Level Electrical Engineering Courses Completely Online", Journal of Online Engineering Education, 2(2) 2011. 